\title{
Identifying Solutions to Psychological Insulin Resistance: An International Study
}

William H. Polonsky, ${ }^{1,2}$ Lawrence Fisher, ${ }^{3}$ Heather Stuckey, ${ }^{4}$ Danielle Hessler,${ }^{3}$ Frank J. Snoek, ${ }^{5}$ Irene Hadjiyianni, Dachuang Cao, ${ }^{7}$ Daniel Pollom, ${ }^{7}$ Samaneh Kalirai, ${ }^{7}$ Jasmina Ivanova, ${ }^{8}$ Urvi Desai, ${ }^{9}$ Magaly Perez-Nieves ${ }^{7}$ \begin{tabular}{l}
${ }^{1}$ Behavioral Diabetes Institute, San Diego, USA. ${ }^{2}$ University of California, San Diego, USA. ${ }^{3}$ University of California - San Francisco, San Francisco, USA. ${ }^{4}$ Pennsylvania State University, Hershey, USA. \\
\hline
\end{tabular}

\section{BACKGROUND}

Adults with type 2 diabetes (T2D) are often reluctant to begin basal insulin therapy, and approximately $30 \%$ refuse to do so after it is recommended by their health care professional (HCP).

Once insulin is initiated, a significant number of T2D adults discontinue use for a period of time, contributing to long periods of hyperglycemic exposure.

- Numerous studies have examined this phenomenon, known as "psychological insulin resistance" or PIR, and have documented the major reasons why these patients are reluctant to begin and sustain insulin use (e.g., injection anxiety)., However, there is little information about what HCPs can do to help these patients. - One approach is to document the types of HCP statements or actions that initially reluctant patients report helped them to finally begin insulin use. This may provide HCPs with strategies that will facilitate a speedier transition to insulin use.

\section{OBJECTIVE}

The EMOTION study (AccEpting Insulin TreatMent for Reluctant PeOple with Type 2 Dlabetes Mellitus - A GIObal Study to IdeNtify Effective Strategies) is a large-scale, seven-country study of T2D adults who initially displayed significant PIR, but who eventually began regular insulin use.

These individuals were asked to identify those specific HCP statements and actions that helped them to overcome their initial reluctance.

\section{METHODS}

- T2D adults were recruited from multiple sources across seven countries. Subject selection was limited to those who indicated an initial reluctance to beginning basal insulin treatment, but then eventually agreed to do so (within 3 years prior to survey completion).

All subjects completed an online, 30-minute survey that captured information on demographic and clinical characteristics, thoughts and feelings about insulin before and after initiation, current insulin use, and, a new 38-item scale (based on qualitative patient and HCP interviews conducted earlier) that included HCP statements and actions regarding insulin initiation that may have occurred during medical visits (the "PIR action survey").

- PIR Action Survey. Each item was rated on a 5-point Likert scale: 1 (did not occur) to 5 (did occur, and helped a lot)

- Occurrence. Frequency of items occurring was evaluated by dichotomizing the response options as 0 ("did not occur") and 1 ("did occur").

- Helpfulness. Degree of helpfulness was evaluated using a 4-point score for those items that occurred: $1=$ not helpful to; $4=$ helped a lot

Exploratory factor analyses (Principal Component Analysis, with Promax rotation) were conducted to determine the key HCP action/statement themes.

\section{RESULTS}

\section{Patient Characteristics}

594 T2D adults from seven nations completed the survey: United States $(n=120)$, Canada $(n=74)$, United Kingdom $(n=125)$, Germany $(n=75)$, Spain $(n=66)$, Brazil $(n=35)$ and Japan $(n=99)$. Patient characteristics are detailed in Table 1.

\section{Table 1: Patient Characteristics}

\begin{tabular}{l|c}
\hline Characteristic & $(n=594)$ \\
\hline Age, mean (SD) & $53.3(11.3)$ \\
\hline Male gender, \% & $57 \%$ \\
\hline Years since diabetes diagnosis, mean (SD) & $8.2(7.4)$ \\
\hline BMI (kg/m²), mean (SD) & $29.8(7.4)$ \\
\hline HbA1c value (\%) prior to insulin initiation, mean* (SD) & $9.8 \%(2.8)$ \\
\hline
\end{tabular}

HbA1c value (\%) prior to insulin initiation, mean* ${ }^{*}(\mathrm{SD})$

${ }^{*}$ Reported for 370 patien

\section{Occurrence of HCP Actions}

- The most frequently occurring items primarily focused on HCP efforts to explain the potential value of starting insulin (e.g., "My HCP told me that my blood glucose numbers would improve after I started insulin") and to provide greater understanding and confidence around the injection process (e.g., "My HCP walked me through the whole process of exactly how to take insulin")

In contrast, the least frequently occurring items focused on threatening statements by HCPs (e.g., "My HCP said that he/she could not continue to treat me if I refused to start insulin"), and on efforts to refer patients to other sources for information (e.g., "My HCP referred me to a class to help me learn more about insulin")

\section{Helpfulness of HCP Actions}

- Items reported to be most helpful aimed at promoting greater understanding and confidence around the injection process. In contrast, items reported to be the least helpful included authoritarian statements and referrals to other sources for information.
Findings from Factor Analysis

Factor analysis of the 38 items (see Table 2) detected 5 subscales (all eigenvalues $>1.00,59.3 \%$ variance explained)

Table 2. Principal Factor Analysis with Promax Rotation

\begin{tabular}{|c|c|c|c|c|c|}
\hline Description & \begin{tabular}{|c|} 
Factor 1: \\
Demonstrated \\
the Injection \\
Process \\
\end{tabular} & $\begin{array}{l}\text { Factor 2: } \\
\text { Dispelled } \\
\text { Insulin } \\
\text { Myths } \\
\end{array}$ & $\begin{array}{l}\text { Factor } 3: \\
\text { Explained } \\
\text { Insulin } \\
\text { Benefits }\end{array}$ & \begin{tabular}{|c|} 
Factor 4: \\
Collaborative \\
Style
\end{tabular} & $\begin{array}{c}\text { Factor 5: } \\
\text { Authoritarian } \\
\text { Style }\end{array}$ \\
\hline My HCP showed me how small the actual needle was & 0.80 & -0.01 & -0.12 & 0.11 & 0.12 \\
\hline $\begin{array}{l}\text { My HCP helped me to see that an insulin injection wasn't as painful } \\
\text { as I thought it might be }\end{array}$ & 0.79 & 0.07 & -0.12 & 0.07 & 0.13 \\
\hline My HCP walked me through the whole process of exactly how to take insulin & 0.66 & -0.04 & 0.28 & -0.01 & -0.14 \\
\hline My HCP showed me an insulin pen & 0.68 & -0.12 & 0.13 & 0.10 & -0.10 \\
\hline My HCP had me try an injection myself while I was there in the office & 0.72 & 0.20 & -0.09 & -0.16 & 0.04 \\
\hline My HCP helped me to see how simple it was to inject insulin & 0.78 & 0.02 & 0.19 & -0.10 & -0.03 \\
\hline My HCP explained that I might not have to take insulin forever & 0.01 & 0.71 & 0.11 & -0.04 & -0.13 \\
\hline $\begin{array}{l}\text { My HCP helped me to realize that insulin wasn't going to cost me as much } \\
\text { money as I feared it would }\end{array}$ & 0.07 & 0.80 & 0.03 & -0.11 & -0.09 \\
\hline $\begin{array}{l}\text { My HCP helped me to recognize that insulin was more natural than the pills } \\
\text { I was taking }\end{array}$ & -0.05 & 0.57 & 0.34 & 0.00 & -0.02 \\
\hline $\begin{array}{l}\text { My HCP told me that by going on insulin, I might soon be able to discontinue } \\
\text { other diabetes medications }\end{array}$ & -0.07 & 0.56 & 0.38 & -0.07 & 0.05 \\
\hline $\begin{array}{l}\text { My HCP reassured me that he/she would help me to avoid or minimize } \\
\text { any weight gain because of taking insulin }\end{array}$ & 0.07 & 0.57 & 0.05 & 0.19 & 0.01 \\
\hline $\begin{array}{l}\text { My HCP and I talked about the real costs of insulin and insulin supplies; } \\
\text { and together we figured out a way to make it more affordable for me }\end{array}$ & -0.02 & 0.69 & -0.12 & 0.15 & 0.05 \\
\hline $\begin{array}{l}\text { My HCP helped me to get over my fears that others would treat me differently } \\
\text { because I was taking insulin }\end{array}$ & 0.06 & 0.60 & -0.17 & 0.17 & 0.10 \\
\hline $\begin{array}{l}\text { My HCP told me that my blood glucose numbers would improve after } \\
\text { I started insulin }\end{array}$ & 0.06 & -0.01 & 0.69 & 0.07 & -0.01 \\
\hline My HCP explained that insulin was a natural substance that my body needed & 0.05 & 0.06 & 0.67 & 0.05 & 0.04 \\
\hline My HCP told me that starting insulin would help me to feel better & 0.01 & -0.03 & 0.73 & 0.08 & 0.15 \\
\hline $\begin{array}{l}\text { My HCP told me that starting insulin could help me to live a longer } \\
\text { and healthier life }\end{array}$ & -0.03 & 0.12 & 0.74 & 0.05 & 0.09 \\
\hline $\begin{array}{l}\text { My HCP took the time to ask me about the reasons why I did not want } \\
\text { to take insulin }\end{array}$ & -0.04 & 0.15 & -0.11 & 0.77 & 0.05 \\
\hline $\begin{array}{l}\text { My HCP encouraged me to try it for a while and see if it might help me } \\
\text { to feel better }\end{array}$ & 0.03 & 0.17 & 0.07 & 0.56 & 0.13 \\
\hline $\begin{array}{l}\text { My HCP explained to me that the final decision to try insulin was mine, } \\
\text { not his/hers }\end{array}$ & -0.07 & 0.01 & 0.09 & 0.71 & 0.05 \\
\hline $\begin{array}{l}\text { My HCP took time to answer all my questions and address my concerns } \\
\text { about insulin }\end{array}$ & 0.01 & 0.00 & 0.24 & 0.67 & -0.10 \\
\hline $\begin{array}{l}\text { My HCP encouraged me to contact his/her office immediately if I ran into } \\
\text { any problems or had questions after starting insulin }\end{array}$ & 0.13 & -0.12 & 0.19 & 0.65 & -0.19 \\
\hline $\begin{array}{l}\text { My HCP warned me that he/she could not be responsible for what might } \\
\text { happen if I did not start insulin soon }\end{array}$ & -0.03 & 0.18 & 0.02 & -0.03 & 0.71 \\
\hline $\begin{array}{l}\text { My HCP said that he/she could not continue to treat me if I refused } \\
\text { to start insulin }\end{array}$ & 0.07 & 0.01 & 0.02 & -0.07 & 0.81 \\
\hline $\begin{array}{l}\text { Repeatedly over many visits, My HCP kept trying to convince me to } \\
\text { started on insulin }\end{array}$ & -0.01 & -0.19 & 0.16 & 0.05 & 0.83 \\
\hline
\end{tabular}

Occurrence of Subscales and Mean Level of Helpfulness, among Those with $\geq 1$ Item Occurring

Mean levels of helpfulness were highest for Demonstrated the Injection Process, Explained Insulin Benefits and Collaborative Style. Lower levels of helpfulness were observed for Dispelled Insulin Myths and the lowest levels for Authoritarian Style (Table 3).

Approximately $90 \%$ or more of patients reported that at least one or more of the items in each of the subscales had occurred, except for Authoritarian Style, where only $54 \%$ of patients reported at least one or more of the subscale items occurring.

Table 3. Occurrence of Subscales and Mean Level of Helpfulness, among Those with $\geq 1$ Item Occurring

\begin{tabular}{l|c|c} 
& $\begin{array}{c}\text { Percent of pattients with } \geq 1 \text { item } \\
\text { occurring } \\
(\% \text { of total n=594) }\end{array}$ & $\begin{array}{c}\text { Helpfulness } \\
\text { Mean (SD) }\end{array}$ \\
\hline Demonstrated the Injection Process & $94 \%$ & $3.07(0.74)$ \\
\hline Explained Insulin Benefits & $97 \%$ & $2.97(0.74)$ \\
\hline Collaborative Style & $95 \%$ & $2.92(0.78)$ \\
\hline Dispelled Insulin Myths & $89 \%$ & $2.77(0.72)$ \\
\hline Authoritarian Style & $54 \%$ & $2.63(0.85)$ \\
\hline $1=$
\end{tabular}

\section{CONCLUSIONS}

While all patients reported a range of strategies that helped them to begin insulin, efforts to address injection concerns by demonstrating the actual injection process, explaining the benefits of insulin and adopting a collaborative, communication style were seen as the most helpful. Elements of each of these three strategies were reported to occur in approximately $90 \%$ or more of patients.

Of the five strategies that were identified, use of an authoritarian communication style was the least helpful and occurred much less frequently than the other four strategies.

This study provides the first evidence regarding potentially useful strategies for overcoming PIR, and is a critical step towards the design of effective intervention protocols and broader clinical recommendations for HCPs.

\section{REFERENCES}

Hosomura N. et al. Diabet. Med. 2017; DOI: 10.1111/dme.13454

Yavuz DG, Ozcan S, Deyneli O. Patient Preference and Adherence 2015;9:1225-1231 Polonsky WH, Hajos TRS, Dain M, Snoek FJ. Current Medical Research \& Opinion 2011 Polonsky WH, et al. Diabetes Care 2005;28:2543-2545
Scan for poster and presented at IDF 2017 